\title{
Carbon Footprint and Responsiveness Trade-offs in Supply Chain Network Design
}

Joana M. Comas Martí ${ }^{a}$, Jean-Sébastien Tancrez ${ }^{a b *}$, Ralf W. Seifert ${ }^{a c}$

a College of Management of Technology

Ecole Polytechnique Fédérale de Lausanne (EPFL)

Station 5, 1015 Lausanne, Switzerland

${ }^{b}$ Louvain School of Management

Université catholique de Louvain (UCL)

Chausée de Binche, 151

7000 Mons, Belgium

${ }^{c}$ IMD - International Institute for Management Development

Chemin de Bellerive 23, P.O. Box 915

1001 Lausanne, Switzerland

* Corresponding author

email: js.tancrez@uclouvain.be

phone: +32 65323 538, fax: +3265323 363

\section{Abstract}

Concern related to sustainability and greenhouse gases has grown among citizens as well as firms, which are increasingly committing to carbon emission reduction targets. However, firms' emissions come from direct and indirect sources, and from the different stages of their supply chain. Therefore, comprehensive supply chain approaches are essential to ensure the cost-effectiveness of carbon management strategies. These approaches should capture operational and environmental trade-offs arising from the interaction between different supply 
chain processes such as procurement, manufacturing, transport and inventory management. Considering all these processes, we propose a model for supply chain network design that takes demand uncertainty into account and includes decisions on supply chain responsiveness under different carbon policies: caps on supply chain carbon footprints, caps on market carbon footprints, and carbon taxes. Our model supports the analysis of the effect of different policies on costs and optimal network configuration and allows us to distinguish between different product types: functional or innovative products. With detailed numerical examples, we illustrate the type of analysis and managerial insights that can be derived with our model, which include: the assessment of supply chains' potential for carbon abatement, the study of the effect of different carbon policies on supply chain costs and network design, the analysis of the impact of various product characteristics, the test of an alternative profit maximization model, and the determination of the value of a supply chain carbon tax that should induce specific levels of carbon abatement.

Keywords: Supply chain network design; Carbon footprint; Emission policy; Supply chain responsiveness; Functional/innovative products; Green supply chain management.

\section{Introduction}

Consumers are increasingly seeking lower-carbon lifestyles. As recent Carbon Trust research reveals, $45 \%$ of UK shoppers - up from half that rate a year earlier - would be prepared to stop buying their favourite brands if the companies refused to commit to measuring their product carbon footprint (The Carbon Trust, 2011a). This consumer pressure explains the increasing resources that organisations are dedicating to carbon accounting, also called carbon footprinting, and, more generally, to carbon management.

Despite the limited reach of current carbon regulation, firms' commitment to meet voluntarily set environmental performance targets is becoming common practice (Comas Martí and Seifert, 2013). An indication of the adoption of such targets is that 59\% of FTSE 100 companies have published targets on greenhouse gases, including carbon or energy reductions (The Carbon Trust, 2011b). Companies' greenhouse gas targets tend to focus on emissions related to their own operations, usually including direct emissions from owned or controlled sources and indirect emissions from the generation of purchased electricity or energy in gen- 
eral. However, companies' carbon accounting should include other indirect emissions that occur in a company's supply chain, e.g. caused by raw material and components suppliers, or by outsourced transport. In the future, it is expected that company carbon targets will develop to include such emissions, given the important opportunities they offer for emissions' abatement.

Since companies tend to rely on third-parties for their inbound and outbound logistics, transport emissions are rarely included in companies' carbon targets. In fact, the share of a product carbon footprint represented by transport emissions may significantly vary from one product to another depending, for instance, on the product's volume or weight, but more importantly on the employed mode of transport. In general, the trade-off in transport is that greater speed relates to greater emissions and greater costs (e.g. air freight compared to sea freight).

However, fast deliveries pay off for certain products; typically for those with high profit margins, with demand patterns that are difficult to predict and with high inventory costs (e.g. due to high obsolescence rates). According to the product characterisation proposed by Fisher (1997), these products are denoted innovative products, whereas those with low profit margins, low demand uncertainty and low inventory holding costs are denoted functional products. As Fisher (1997) explains, innovative products require responsive supply chains with short lead times in order to minimise stockouts, forced markdowns and obsolete inventory. Conversely, functional products require physically efficient supply chains primarily focused on cost, with less emphasis on lead time.

The level of responsiveness of a supply chain is not only determined by transport mode decisions, but also by other factors such as the location of its facilities. However, in facility location decisions, not only the nature of the product (innovative or functional) intervenes; manufacturing and raw material costs are also important factors (Krugman and Venables, 1995; Alonso-Villar, 2005). Especially for labour-intensive industries (e.g. apparel and electronics), manufacturing in low-wage countries can be very attractive despite them being far away from the markets where products are sold.

Therefore, we observe that there are opportunities for the companies wanting to reduce carbon emissions in looking beyond their own operations and consider indirect emissions from other processes in their supply chains such as transport emissions. However, we also observe 
that it is not easy for these companies to balance carbon considerations with supply chain responsiveness trade-offs and differences in manufacturing costs around the globe, as emissions and costs from different processes are interconnected. Moreover, as we explained, functional and innovative products have different requirements in terms of supply chain responsiveness. Thus, it is reasonable to think that the strategy to reduce the emissions closely depends on the product's characteristics: the emissions from a supply chain delivering a functional product and from a supply chain delivering an innovative product might be very different.

In this article, we present a mathematical model to assist companies facing these joint environmental and operational trade-offs, and help them define carbon abatement strategies in a cost-effective manner. More precisely, we contribute to the literature with a supply chain network design model that simultaneously considers the emissions and costs related to both facility location and transport mode decisions, while taking into account the innovative or functional nature of products through the explicit consideration of demand uncertainty and inventory costs. We explicitly model differences across facility locations in terms of costs/emissions of raw materials or components, manufacturing technologies and labour.

The structure of this article is as follows. In Section 2, we discuss previous literature relevant to our research. In Section 3, we present our integer programming formulation of the problem considered. In Section 4, we present detailed numerical analyses to illustrate the relevance of the trade-offs captured by the model and the type of managerial insights that it allows to derive. In Section 5, we conclude and discuss future research opportunities.

\section{Literature review}

A key feature of the model presented in this article is its comprehensiveness. The model aims to integrate carbon emission reduction policies in a supply chain network design framework that simultaneously captures facility location and transport mode decisions, which determine supply chain lead time and inventory levels. In the literature, we can find prior contributions covering one or more of these different aspects, although not all of them simultaneously. In this section, we go through prior research relevant to the trade-offs captured in our model.

First, we review contributions in the supply chain network design literature that do not include environmental aspects. We focus on literature relevant to the trade-offs of interest, i.e. transport mode choice and supply chain responsiveness. Baumol and Vinod (1970) set the 
basis for transport mode choice models. This body of literature explicitly takes into account demand uncertainty when studying the value of shorter lead times (Tyworth, 1991; Meixell and Norbis, 2008). As Blauwens et al. (2006) explain, the crux of the inventory theoretic approach lies in the fact that explicit attention is paid to all costs in the supply chain that are affected by the choice of transport mode. However, it is rare for supply chain network design models to jointly capture transport mode and facility location decisions. Wilhelm et al. (2005) present one such model, taking into account transport mode capacities and both fixed and variable costs. Carlsson and Rönnqvist (2005) also consider both types of decisions for a case study of a forestry company. However, these models assume deterministic demand, whereas ours takes into account demand uncertainty, which is highly relevant, as emphasised in the transport mode choice literature.

As noted earlier, demand uncertainty is particularly high for innovative products and lower for functional ones. As Fisher (1997) explains, demand uncertainty, holding costs and inventory costs are important factors to be considered when defining supply chain strategies. Langenberg et al. (2012) and Seifert and Langenberg (2011) provide quantitative support for Fisher's qualitative framework. They present supply chain network design models that explicitly capture supply chain lead time and responsiveness decisions, and take into account demand uncertainty. We extend this modelling approach by incorporating carbon footprints and carbon policies, by capturing transport mode decisions and also by explicitly modelling geographical differences in procurement costs.

We now review the operations management contributions that include carbon emissions and other environmental aspects. Environmental supply chain models (i.e. mathematical models that combine operational and environmental aspects) have been proposed to provide support in different decision-making settings (Dekker et al., 2012).

The selection of manufacturing technologies is one of the decisions that have been studied by these models. The models presented in Bloemhof-Ruwaard et al. (1996) and Hugo and Pistikopoulos (2005) assist in the selection among technologies with different costs and environmental impacts, the latter being captured with indicators based on life cycle assessment (LCA). Drake et al. (2010) focus on technology choices and capacity investments and study how these are affected by emissions regulation.

Inventory level decisions considering carbon emissions have been recently studied by sev- 
eral authors. Assuming deterministic demand, Benjaafar et al. (2013) analyse how simple operational models could be adapted to include carbon footprint parameters. Their goal in this study was to showcase the importance of developing such supply chain models to account for carbon emissions and evaluated the impact of carbon footprint policies. Hua et al. (2011) investigate in detail how various carbon emission reduction policies impact inventory management decisions, using the classical EOQ model as a benchmark. Chen and Monahan (2010) add demand uncertainty to inventory models considering different environmental policies and introduce the term environmental safety stock. In our work, we include inventory decisions in a broader supply chain network design model, and we assume uncertain demand.

Transport mode selection models including carbon policies are presented by Hoen et al. (2014), aiming to study the impact of carbon emission regulation on the traditional tradeoff between lead time and transport costs. Their models take into account product demand uncertainty and capture the effect of transport mode choices on lead time. However, they do not integrate location-allocation decisions, while our models do.

The coverage of facility location and allocation decisions by the supply chain environmental management literature has been mostly within the scope of reverse logistics network design (Fleischmann et al., 1997). This literature is related to green supply chain management in that reverse logistics is directly concerned with efficient recycling, waste management, take-back of products (Srivastava, 2008; Quariguasi Frota Neto et al., 2009) and life-cycle assessment (LCA) (Hugo and Pistikopoulos, 2005; Bloemhof-Ruwaard et al., 1996).

However, supply chain network design models that consider carbon emission reduction are more rare. Few have been proposed recently. Diabat and Simchi-Levi (2009) propose a facility location model minimizing fixed and distribution costs, while constraining carbon emissions coming from warehouses, plants and transport to a cap. Similarly, Wang et al. (2011) extend the classical facility location model to consider carbon emissions, but, rather than adding a cap constraint, they propose a bi-objective model. The first objective minimizes total costs and the second one minimizes carbon emissions coming from facilities and transport. Chaabane et al. (2012) also propose a bi-objective model combining an economic and an environmental objective, but with a more complex formulation (21 decisions variables with indices), and relying on LCA principles. The cost function includes fixed and distribution costs, production costs, reverse logistics and LCA based costs, while the emissions are converted from LCA based 
parameters. Harris et al. (2011) use a simulation model to analyse, in a specific case study from the automotive industry, the relationship between total logistics costs of the network and carbon emissions coming from transportation and depots. None of these four contributions consider inventory, uncertain demand, transport mode decisions, or geographical differences in procurement costs.

The different environmental supply chain models discussed above partially cover one or several of the decisions captured by our model, which are technology selection, inventory levels, transport modes, facility location and allocation decisions. Our model differentiates from this prior research by simultaneously considering all these decisions.

\section{Problem description and model formulation}

In this section, we propose a supply chain network design model that supports the definition of comprehensive and cost-effective carbon management strategies under different carbon policies, while taking product's characteristics into account, in particular related to the innovativeness. Our model provides decision makers with support for decisions on how many facilities should be used for manufacturing (location), which should serve each market (allocation) and which transport modes should be employed, while taking particular types of carbon policies into account. Indirectly, frequency of shipments and market inventory levels are also determined. In addition, these decisions determine the optimal supply chain responsiveness, which is particularly relevant in a setting with product demand uncertainty, and which we characterise through supply chain lead time. To focus on the main trade-offs, in this article, we study the single product problem. In the following, we first introduce our base case model, with no carbon emissions policy in place, and then we add different carbon policies. An overview of notation is provided in Table 1 at the end of this section.

\subsection{Base case model: responsiveness trade-offs}

The base case model captures responsiveness trade-offs balancing supply chain lead time and costs (with no carbon policy) by taking into account inventory, procurement and fixed costs. We use an assignment-based formulation (Sahin and Süral, 2007) in which the binary decision variables $Y_{m f t}$ assign one facility $f$ and one transport mode $t$ to each market $m$, and in which the binary variable $Z_{f}$ indicates whether facility $f$ is used for manufacturing or not. Thus, the base case model is constituted by the following equations: 


$$
\begin{aligned}
\min _{Y_{m f t}, Z_{f}} & \sum_{m, f, t} \text { unitcost } t_{m f t}^{C} \lambda_{m} Y_{m f t}+\sum_{f} c_{f}^{F} Z_{f} \\
\text { s.t. } & \sum_{f, t} Y_{m f t}=1 \quad \forall m \\
& M^{b i g} Z_{f} \geq \sum_{m, t} Y_{m f t} \quad \forall f
\end{aligned}
$$

The cost function (1) captures total supply chain costs per unit of time on the assumption that demand in markets is stationary and stochastic, with mean demand rate $\lambda_{m}$. As is common in facility location models, fixed charges of running facilities $\left(c_{f}^{F}\right)$ are included. The total variable cost for supplying one unit, unitcost ${ }_{m f t}^{C}$, can be decomposed into inventory costs (holding costs in markets' warehouses and in transit, as well as ordering and shortage costs) and procurement costs (raw materials, manufacturing including labour and transport).

$$
\begin{aligned}
\text { unitcost }_{m f t}^{C}= & \text { warehousing }_{m f t}^{C}+\text { in_transit }_{m f t}^{C}+\text { ordering }_{m f t}^{C}+\text { shortage }_{m f t}^{C}+ \\
& + \text { raw_materials }{ }_{f}^{C}+\text { manufacturing } \\
\text { C } & + \text { transport }_{m f t}^{C}
\end{aligned}
$$

Constraint (2) ensures each market is assigned to one and only one facility and transport mode. Constraint (3) relates variables $Z_{f}$ and $Y_{m f t}$. Next, we explain different cost terms and the practical issues that they capture.

\subsubsection{Inventory costs}

Regarding inventory decisions, we take demand uncertainty into account and we use a continuous review inventory policy, i.e. the classical quantity-reorder point policy of Hadley and Whitin (1963), on the assumption that demands occurring when the system is out of stock are backordered. The order quantity $Q_{m f t}$ and the reorder point $R_{m f t}$ are computed as follows.

$$
\begin{aligned}
Q_{m f t} & =\sqrt{\frac{2 \lambda_{m}\left(K_{m f t}+\pi_{m} n_{m f t}\right)}{h_{m}}} \quad \forall m, f, t \\
\frac{Q_{m f t} h_{m}}{\pi_{m} \lambda_{m}} & =1-F_{m f t}^{\tau}\left(R_{m f t}\right) \quad \forall m, f, t \\
n_{m f t} & =\int_{R_{m f t}}^{\infty}\left(x-R_{m f t}\right) f_{m f t}^{\tau}(x) d x \quad \forall m, f, t
\end{aligned}
$$

The demand over lead time distribution functions are denoted $f_{m f t}^{\tau}(x)$ (density) and $F_{m f t}^{\tau}(x)$ (cumulative), while $n_{m f t}$ denotes the average number of shortages per ordering cycle. To be able to solve these equations sequentially, and since it has been shown to be a good approximation (Nahmias, 1997), we use the economic order quantity (EOQ) for $Q_{m f t}$.

In this context, location-allocation decisions and inventory decisions are related since the allocation of market $m$ to facility $f$ and transport mode $t$ determines the supply chain lead time for each market $\tau_{m f t}$, which affects the demand over lead time, and eventually the inventory policy parameters $Q_{m f t}$ and $R_{m f t}$. The supply chain lead time is deterministic 
and depends on manufacturing lead time at a facility $\left(\tau_{f}\right)$, distance between the facility and market locations $\left(d_{m f}\right)$ and transport mode speed $\left(\dot{\tau}_{t}\right): \tau_{m f t}=\tau_{f}+d_{m f} \dot{\tau}_{t}$.

Equations (5-6) allows us to obtain $Q_{m f t}$ and $R_{m f t}$ a priori for each possible market-facilitytransport combination and use these values as inputs in our cost function. Warehousing costs depend on the warehousing cost per unit $\left(h_{m}\right)$ and on the average inventory levels in markets, which include average cycle stock $\left(Q_{m f t} / 2\right)$ and safety stock $\left(R_{m f t}-\tau_{m f t} \lambda_{m}\right)$. In-transit costs are proportional to the in-transit carrying cost per unit of product per period $\left(r_{m}\right)$ and to the supply chain lead time $\left(\tau_{m f t}\right)$. Ordering costs $\left(K_{m f t}\right)$ cover the administrative costs of ordering one shipment including border-crossing costs. Shortage costs are caused by unfulfilled market demand, leading to a penalty cost $\left(\pi_{m}\right)$. We get the following inventory cost terms:

$$
\begin{aligned}
\text { warehousing }_{m f t}^{C} & =\frac{h_{m}}{\lambda_{m}}\left(\frac{Q_{m f t}}{2}+R_{m f t}-\lambda_{m} \tau_{m f t}\right) \quad \forall m, f, t \\
\text { in_transit }_{m f t}^{C} & =r_{m} \tau_{m f t} \quad \forall m, f, t \\
\text { ordering }_{m f t}^{C} & =\frac{K_{m f t}}{Q_{m f t}} \quad \forall m, f, t \\
\text { shortage }_{m f t}^{C} & =\frac{\pi_{m} n_{m f t}}{Q_{m f t}} \quad \forall m, f, t
\end{aligned}
$$

In order to define the warehousing cost per unit of product held in a market $m$ per unit of time $\left(h_{m}\right)$, we distinguish a non-energy and an energy component: $h_{m}=h_{m}^{0}+h_{m}^{e} p_{m}^{e}$. The non-energy component $\left(h_{m}^{0}\right)$ typically includes product deterioration and obsolescence costs, the financial costs of holding inventory and non-energy physical storage costs. The energy component, by contrast, includes the energy consumption arising from the storage of products in market warehouses $\left(h_{m}^{e}\right.$, which can vary with product volume and storage requirements such as temperature and humidity specifications) and the energy prices in markets $\left(p_{m}^{e}\right)$.

\subsubsection{Procurement costs}

Within procurement costs, we capture three types of costs that economic geography scholars have shown to be relevant to industry location: raw material, manufacturing and transport costs (Krugman and Venables, 1995; Alonso-Villar, 2005). As previously, for the warehousing cost, we explicitly distinguish between non-energy and energy components. This will later allow us to include a carbon tax on energy prices (see Section 3.2.3).

First, raw material costs include all processes upstream of facilities. The non-energy cost $\left(c_{f}^{r}\right)$ and energy intensity $\left(c_{f}^{r e}\right)$ of sourcing raw materials (or components) from suppliers are strongly affected by factor endowments such as access to resources. Second, we decompose manufacturing costs as proportional to labour costs at facilities $\left(c_{f}^{l}\right)$, as geographical wage differences have played an increasing role in industry location (Krugman and Venables, 1995), 
and proportional to energy consumption $\left(c_{f}^{e}\right)$, as it can be influenced by environmental stringency or laxity in different regions. For raw material and manufacturing energy costs, different levels of access to energy resources across regions affect energy prices $\left(p_{f}^{e}\right)$. Third, transport costs are proportional to product weight $(w)$ and distance travelled between facilities and markets $\left(d_{m f}\right)$. They are variable, as we assume that transport capacity is shared with the firms' other products or outsourced to a third-party logistics (3PL) provider. Moreover, transport costs depend on the transport mode used, which determine non-energy transport prices $\left(\dot{c}_{t}^{0}\right)$ and energy intensity $\left(\dot{c}_{t}^{e}\right)$. Following common practice, we define energy intensity per tonne of product transported and per kilometre travelled. Finally, we get the following procurement cost terms:

$$
\begin{array}{rlll}
\text { raw_materials }_{f}^{C} & =c_{f}^{r}+c_{f}^{r e} p_{f}^{e} \quad \forall f & \\
\text { manufacturing }_{f}^{C} & =c_{f}^{l}+c_{f}^{e} p_{f}^{e} \quad \forall f & \\
\text { transport }_{m f t}^{C} & =\left(\dot{c}_{t}^{0}+\dot{c}_{t}^{e} p_{t}^{e}\right) w d_{m f} & \forall m, f, t
\end{array}
$$

\subsection{Integrating carbon footprint trade-offs}

In order to support the definition of cost-effective carbon abatement strategies, we now include carbon emissions and policies into the base case model. As discussed in our introduction, despite the limited reach of carbon regulation to date, voluntary policies are increasingly used, with footprinting and target definition becoming common practice.

In our model, we take into account the emissions from various supply chain processes that can potentially be affected by the network design decisions considered, i.e. facility location, market allocation and transport mode. Thus, we consider emissions from warehousing, raw materials, manufacturing and transport. We use the term product carbon footprint (PCF) to refer to the above emissions associated with one unit of product sold in a market $m$.

$$
P C F_{m}\left(Y_{m f t}\right)=\sum_{f} \sum_{t}\left(\text { raw_materials }_{f}^{\varepsilon}+\text { warehousing }_{m f t}^{\varepsilon}+\text { manufacturing }_{f}^{\varepsilon}+\text { transport }_{m f t}^{\varepsilon}\right) Y_{m f t}
$$

We calculate these emission terms in coherence with the computation of cost terms. Raw materials emissions $\left(\varepsilon_{f}^{r}\right)$ include emissions from processes upstream of facilities in the supply chain, while manufacturing emissions $\left(\varepsilon_{f}\right)$ focus on the facility. Emissions at warehouses $\left(\varepsilon_{m}^{h}\right)$ are proportional to inventory levels, and transport emissions $\left(\dot{\varepsilon}_{t}\right)$ are proportional to product weight and distance. Hence, we get the following emission terms:

$$
\begin{aligned}
\text { warehousing }_{m f t}^{\varepsilon} & =\frac{\varepsilon_{m}^{h}}{\lambda_{m}}\left(\frac{Q_{m f t}}{2}+R_{m f t}-\lambda_{m} \tau_{m f t}\right) \quad \forall m, f, t \\
\text { raw_materials }_{f}^{\varepsilon} & =\varepsilon_{f}^{r} \quad \forall f \\
\text { manufacturing }_{f}^{\varepsilon} & =\varepsilon_{f} \quad \forall f \\
\text { transport }_{m f t}^{\varepsilon} & =\dot{\varepsilon}_{t} w d_{m f} \quad \forall m, f, t
\end{aligned}
$$


Different greenhouse gases are captured with these emission terms - all expressed in units of mass of carbon dioxide equivalent (e.g. $\mathrm{kgCO}_{2}$ ). Although we focus on carbon emissions, this formulation applies to other types of emissions or environmental aspects relevant to the processes considered.

\subsubsection{SCCFC: supply chain carbon footprint cap}

Having presented the emission sources that we take into account, the first policy variant that we consider is the one offering the greatest degree of flexibility. A cap, called supply chain carbon footprint cap (SCCFC), is imposed on the sum of all carbon footprints for all units of product sold in all markets. We model it by adding the following constraint to the base case model.

$$
\sum_{m} \lambda_{m} P C F_{m}\left(Y_{m f t}\right) \leq S C C F C
$$

In practice, firms tend to define these caps as a reduction target based on the supply chain emissions in a particular base year (The Carbon Trust, 2011b). With this policy, the most cost-effective reductions can be achieved, as it is possible to balance emissions caused by different markets, which may be assigned to different transport modes and to different facilities with their respective carbon intensities and distances.

\subsubsection{MCFC: market carbon footprint cap}

The second policy variant that we study is the definition of a cap at the market level. A cap, called the market carbon footprint cap (MCFC), is imposed on the sum of carbon footprints for all units of product sold in a particular market. In this case, we add the following constraints to the base case model.

$$
\lambda_{m} P C F_{m}\left(Y_{m f t}\right) \leq M C F C_{m} \quad \forall m
$$

The underlying reasons for firms to define this type of policy is to display product carbon footprint labels (The Carbon Trust, 2011a), which can be adapted to different levels of customer environmental awareness across markets. It can also be used to satisfy regulatory carbon caps in different regions. The drawback of this policy compared to an SCCFC, is that it is more constraining: compensation of emissions across markets is no longer possible. With the MCFC, markets may source from various channels but each market has to satisfy a given cap. With the SCCFC, markets may also source from various channels but each market's emissions are not constrained: the cap is set at the global supply chain level. More options are thus open with the SCCFC than with the MCFC and, at the same global level of emissions, the total supply chain costs will typically be smaller with the SCCFC (also see Section 


\subsubsection{SCCFT: supply chain carbon footprint tax}

Finally, we study the supply chain carbon footprint tax (SCCFT) case, which consists of imposing a common tax for all emissions in the whole supply chain. Since in the base case we explicitly take energy consumption costs into account, the different taxes on emissions from manufacturing, transport and/or warehousing can be modelled as a direct extension. To account for the taxes, the energy prices at facilities, for transport and in markets $\left(p_{f}^{e}, p_{t}^{e}\right.$ and $\left.p_{m}^{e}\right)$ are modified to adjusted prices $\left(\tilde{p}_{f}^{e}, \tilde{p}_{t}^{e}\right.$ and $\left.\tilde{p}_{m}^{e}\right)$, by adding a supplementary term. To compute this additional term, we multiply the taxes on carbon emissions $\left(p_{f}^{\varepsilon}, p_{t}^{\varepsilon}\right.$ and $p_{m}^{\varepsilon}$, in $\left.€ / \mathrm{kgCO}_{2}\right)$ by conversion factors relating carbon emissions and energy consumption $\left(e_{f}^{\varepsilon}, e_{t}^{\varepsilon}\right.$ and $e_{m}^{\varepsilon}$ in $\mathrm{kgCO}_{2} / \mathrm{kg}$ fuel).

$$
\tilde{p}_{f}^{e}=p_{f}^{e}+e_{f}^{\varepsilon} p_{f}^{\varepsilon} \quad \forall f \quad ; \quad \tilde{p}_{t}^{e}=p_{f}^{e}+e_{t}^{\varepsilon} p_{t}^{\varepsilon} \quad \forall t \quad ; \quad \tilde{p}_{m}^{e}=p_{m}^{e}+e_{m}^{\varepsilon} p_{m}^{\varepsilon} \quad \forall m
$$

In the supply chain carbon footprint tax (SCCFT) case, all the above emission taxes are constant across facility and market locations, and across transport modes. However note that other carbon tax variants could be modelled using this formulation.

From a facility location point of view, all variants of our formulation presented in Section 3 can be characterised as discrete, static, one-product, uncapacitated, cost minimization problems. The models are linear integer programmes which we can solve with commercial software. For the numerical analyses that we present next, we used the GAMS modelling language and CPLEX 10.0 on a $3.17 \mathrm{GHz}$ computer, with satisfactory computation times of the order of 5-10 seconds per instance.

\section{Numerical analyses}

In this section, we illustrate the use of our model and show that its comprehensiveness through location, allocation, inventory and carbon emission considerations - is indeed needed to balance the complex trade-offs at hand. In our analyses, we exemplify the rich managerial insights that can be derived for a company, when its product characteristics are taken into account. Next, we describe the setting for our numerical analyses and the corresponding supply chains that minimise costs if no carbon policy is in place. In the subsequent subsections, we study the impact of the three carbon policies on the supply chain network design, costs and emissions. We start with an in-depth analysis of the effect of a supply chain carbon footprint cap (SCCFC) and then discuss the market carbon footprint cap (MCFC) and the 


\begin{tabular}{|c|c|c|}
\hline Symbol & Description & Value (Functional, Innovative) \\
\hline \multicolumn{3}{|l|}{ Indices and sets: } \\
\hline$m$ & markets to be served & $\in[1, \ldots, M] ; M=50$ \\
\hline$f$ & facility locations available for manufacturing & $\in[1, \ldots, F] ; F=50$ \\
\hline$t$ & transport modes & $\in\{$ sea, rail, road, air $\}$ \\
\hline \multicolumn{3}{|c|}{ Decision variables (binary): } \\
\hline \multicolumn{3}{|c|}{$\begin{array}{ll}Y_{m f t} & \text { facility and transport } \\
Z_{f} & \text { facility opening }\end{array}$} \\
\hline \multicolumn{3}{|c|}{ Inventory policy (dependent) parameters: } \\
\hline$Q_{m f t}$ & order quantity & (dependent) unit/order \\
\hline$R_{m f t}$ & reorder point & (dependent) unit \\
\hline$n\left(R_{m f t}\right)$ & number of shortages per ordering cycle & (dependent) unit/ordering cycle \\
\hline \multicolumn{3}{|c|}{ Product parameters: } \\
\hline$w$ & product weight & $0.2 \mathrm{~kg}$ \\
\hline \multicolumn{3}{|c|}{ Demand parameters: } \\
\hline$\lambda_{m}$ & mean demand per period & 100 units/day \\
\hline$\sigma^{m} V_{m}$ & $\begin{array}{l}\text { standard deviation of demand per period } \\
\text { coefficient of variation of demand }\end{array}$ & $\begin{array}{l}\lambda_{m} C V_{m} \text { units/day } \\
(0.2,1.5) \text { units } / \text { day }\end{array}$ \\
\hline \multicolumn{3}{|c|}{ Network parameters: } \\
\hline$d_{m f}$ & facility-market distance & (dependent) $\mathrm{km}$ \\
\hline$x_{m}^{m}, y_{m}^{m}$ & market latitude and longitude & $\in[0,2000] ; \in[0,8000] \mathrm{km}$ \\
\hline$x_{f}^{f}, y_{f}^{f}$ & facility latitude and longitude & $\in[0,8000] ; 4000 \mathrm{~km}$ \\
\hline$\tau_{m f t}$ & total lead time & (dependent) day \\
\hline \multicolumn{3}{|c|}{ Market inventory parameters: } \\
\hline$h_{m}^{0}$ & non-energy warehousing costs & $(20 \% \cdot 4 / 365,50 \% \cdot 4.5 / 365) € /$ unit/day \\
\hline$h_{m}^{e}$ & warehousing energy consumption & $0 \mathrm{~kg}$ fuel/unit/day \\
\hline$r_{m}$ & in-transit carrying cost & $(20 \% \cdot 4 / 365,50 \% \cdot 4.5 / 365) € /$ unit/day \\
\hline$K_{m}^{0}$ & non-energy ordering costs & $50 € /$ order \\
\hline$\pi_{m}$ & penalty cost for shortages & $(0.21,3) € /$ unit \\
\hline \multicolumn{3}{|c|}{ Facility parameters: } \\
\hline$c_{f}^{r}$ & raw materials non-energy cost & $2 € /$ unit \\
\hline$c_{f}^{r e}$ & raw materials energy consumption & $0.2 \mathrm{~kg}$ fuel/unit \\
\hline$c_{f}^{l}$ & labour cost & west $=1.5$; east $=0.5 € /$ unit \\
\hline$c_{f}^{e}$ & manufacturing energy consumption & west $=0.2$; east $=0.4 \mathrm{~kg}$ fuel $/$ unit \\
\hline$c_{f}^{F}$ & fixed facility costs & $200 € /$ facility/day \\
\hline$\tau_{f}$ & manufacturing lead time & 2 day \\
\hline \multicolumn{3}{|c|}{ Transport mode parameters: } \\
\hline$\dot{c}_{t}^{0}$ & non-energy transport cost & $0.05 € /$ tonne $/ \mathrm{km}$ \\
\hline$\dot{c}_{t}^{e}$ & transport energy consumption & $\dot{\varepsilon}_{t} / e_{t}^{\varepsilon} \mathrm{kg}$ fuel/tonne $/ \mathrm{km}$ \\
\hline$\tau_{t}^{0}$ & fixed transport lead time & $\{1,5,15,20\}$ day \\
\hline$\dot{\tau}_{t}$ & transport mode speed & $\left\{\frac{1}{25 \cdot 8}, \frac{1}{45 \cdot 8}, \frac{1}{60 \cdot 8}, \frac{1}{250 \cdot 8}\right\}$ day $/ \mathrm{km}$ \\
\hline \multicolumn{3}{|l|}{ Fuel prices: } \\
\hline \multicolumn{3}{|c|}{ Emission parameters: } \\
\hline$e_{f}^{\varepsilon}, e_{t}^{\varepsilon}, e_{m}^{\varepsilon}$ & $\begin{array}{l}\text { emission factor for energy source used at facilities, for } \\
\text { transport and in markets }\end{array}$ & $3.7655 \mathrm{kgCO}_{2} / \mathrm{kg}$ fuel \\
\hline$\varepsilon_{m}^{h}$ & warehousing emissions & $h_{m}^{e} e_{m}^{\varepsilon} \mathrm{kgCO}_{2} /$ unit/day \\
\hline$\varepsilon_{f}^{r}$ & raw material emissions & $c_{f}^{r e} e_{f}^{\varepsilon} \mathrm{kgCO}_{2} /$ unit \\
\hline$\varepsilon_{f}$ & manufacturing emissions & $c_{f}^{e} e_{f}^{\varepsilon} \mathrm{kgCO}_{2} /$ unit \\
\hline$\dot{\varepsilon}_{t}$ & 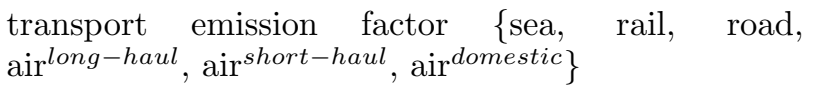 & $\begin{array}{l}\{4.12,36.92,150.54,733.29,1762.43, \\
2345.93\} \mathrm{gCO}_{2} / \text { tonne } / \mathrm{km}\end{array}$ \\
\hline \multicolumn{3}{|c|}{ Carbon policy parameters:: } \\
\hline$S C C F C$ & supply chain carbon footprint cap & $-50 \mathrm{kgCO}_{2}$ (per instance) \\
\hline$M C F C_{m}$ & market carbon footprint cap & $\sum M C F C_{m}=S C C F C$ \\
\hline$p_{f}^{\varepsilon}, p_{t}^{\varepsilon}, p_{m}^{\varepsilon}$ & emissions tax per facility, transport mode and market & {$\left[\mathrm{MAC}\right.$ curve values] $€ / \mathrm{kgCO}_{2}$} \\
\hline
\end{tabular}

Table 1: Summary of notation and input data for numerical analyses. 
supply chain carbon footprint tax (SCCFT).

\subsection{Setting description}

In this subsection, we describe the setting for our numerical analyses, which aim to illustrate how our approach can be used in various particular cases. We also explain our numerical choices for the most relevant parameters. All parameter values are detailed in Table 1.

Given the importance of responsiveness in our study, we conduct numerical analyses for two stylised supply chains; one providing a given functional product and another providing a given innovative product. The numerical setting is inspired in the apparel sector, with for example a classic (e.g. a white t-shirt) and a fashion item of clothing (e.g. the latest trend top). Following Fisher (1997), we define two typical product profiles: a functional product with a low coefficient of variation of demand $\left(C V_{m}=0.2\right)$ and a small profit margin (5\%); and an innovative product with an uncertain demand $\left(C V_{m}=1.5\right)$ but a large profit margin (40\%) due to less competition. We use an average cost of goods sold of 4 and 4.5 $€$ per unit of functional and innovative product respectively. This difference arises from the fact that it is more expensive to provide innovative products, as our results show. Thus, sales prices can be calculated - they are $4.21 €$ for the functional product and $7.5 €$ for the innovative one. Holding costs include opportunity and obsolescence costs, and are thus higher for the innovative product (50\%) than for the functional product (20\%). Penalty costs are set to be equal to profit margins, i.e. 0.21 and $3 € /$ unit respectively. Since demand for innovative products is considerably uncertain, we use the lognormal distribution for demand $\left(\lambda_{m}=100\right.$ units/day), and thus demand over lead time also follows a lognormal distribution (Tadikamalla, 1984).

To illustrate our approach, we consider a hypothetical global firm with markets located in western regions, aiming to design its supply chain network while minimising total costs and respecting carbon policy requirements. The geographical setting, the distances, the 50 market locations and the 50 potential facility locations are illustrated in Figure 1. For simplicity, we suppose that all product types (functional or innovative) can be sourced from any of these 50 potential facility locations. Note that, in other cases, some products, innovative in particular, could require specialized competence and be sourced only from specific technology districts (Storper, 1992). This could be modelled using our formulation by limiting the number of 
potential locations, or by increasing the fixed charges for running facilities at some locations $\left(c_{f}^{F}\right)$. Focusing on the trade-offs that interest us, we model geographical differences in labour cost and emissions. In particular, we model east-west wage differences by assuming that labour unit costs progressively decrease with facility longitudes from $1.5 € /$ unit in the most western facility location to $0.5 € /$ unit in the most eastern one. Manufacturing energy intensity, by contrast, increases from west to east, from 0.2 to $0.4 \mathrm{~kg}$ of fuel per unit, since we assume western facilities are more efficient, e.g. due to more stringent standards. We consider four transport modes. From slowest to fastest, from cheapest to most expensive, and from least to most polluting, they are: sea, rail, road and air transport. We use classic average speeds per mode of $25,45,60$ and $250 \mathrm{~km} / \mathrm{h}$.

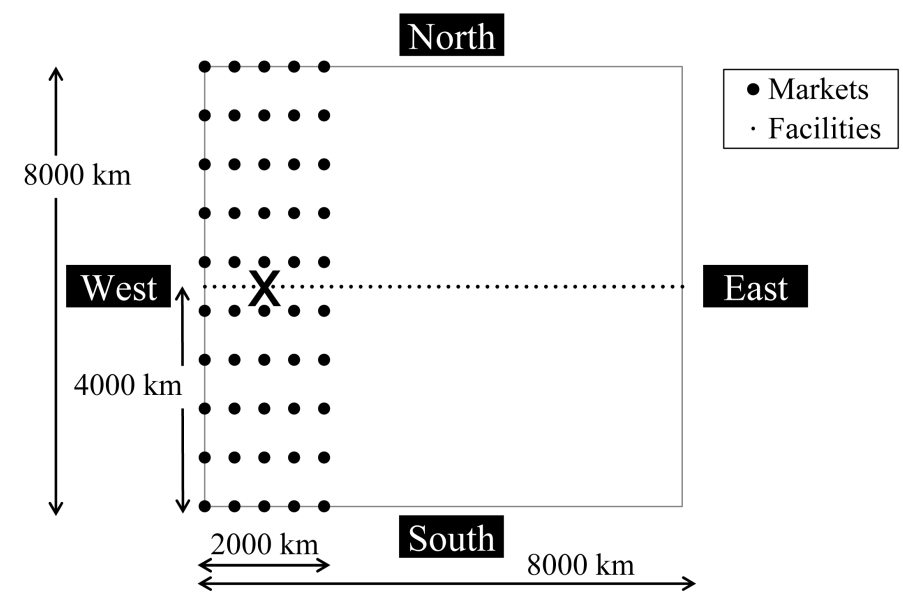

Figure 1: Geographical locations of markets (large dots) and potential facilities (small dots).

With regard to emission parameters, different calculation approaches and emission factors are available to date to compute greenhouse gas emissions with different levels of detail (GHG Protocol, 2004; IPCC, 2006; BSI, 2008; Defra, 2010). We use transport emission factors $\left(\dot{\varepsilon}_{t}\right)$ from Defra (2010), a comprehensive source that accounts for multiple greenhouse gases, includes both direct and indirect emissions, and has a level of aggregation that is appropriate for our strategic problem. Regarding raw material and manufacturing emissions, fuel-based approaches to estimating greenhouse gas emissions are well established (IPCC, 2006). We use them to calculate emission intensities directly from fuel consumption. This assumption allows us to use only one factor, and leads to manufacturing energy costs and emissions being directly proportional. We choose this assumption for simplicity and as it is supported by the 
literature, but we note that our model could support non-proportional energy $\operatorname{costs}\left(c_{f}^{e} p_{f}^{e}\right)$ and emissions $\left(\varepsilon_{f}\right)$, and energy factors that depend on the facility location. In particular, we assume fuel oil is the sole energy source and we use its emission factor of $3.7655 \mathrm{kgCO}_{2} / \mathrm{kg}$ fuel to convert from energy to emissions, and vice versa (Defra, 2010). Although our model allows us to consider energy consumption and emissions at warehouses, to focus on our main trade-off, we will neglect them in these numerical analyses. Finally, the price of fuel oil is set at $1.5 € / \mathrm{kg}$.

\subsection{Base case for both product types}

Before we analyse the effect of the different carbon policies, we first apply our methodology for the two products, functional and innovative, considering only costs but no carbon policy. We denote this setting as the base case. A summary of supply chain characteristics for the base case of each product is provided in Table 2. On the left-hand side of Figure 2, the facility locations and transport modes selected for the base case are shown for both products.

\begin{tabular}{|c|c|c|c|c|c|c|}
\hline & \multicolumn{3}{|c|}{ Functional } & \multicolumn{3}{|c|}{ Innovative } \\
\hline & Base case & $-20 \%$ & $-35 \%$ & Base case & $-20 \%$ & $-39 \%$ \\
\hline $\mathrm{SC}$ carbon footprint $\left[\mathrm{tCO}_{2}\right]$ & 11.6 & 9.3 & 7.5 & 15.3 & 12.2 & 9.3 \\
\hline Total costs $[\mathrm{k} €]$ & 18.2 & $+9 \%$ & $+17 \%$ & 21 & $+0.5 \%$ & $+5 \%$ \\
\hline Lead time* [days] & 33 & $-35 \%$ & $-16 \%$ & 6 & $-20 \%$ & $+24 \%$ \\
\hline Distance* $^{*}[\mathrm{~km}]$ & 7445 & $-55 \%$ & $-65 \%$ & 6227 & $-39 \%$ & $-63 \%$ \\
\hline Stock cover* [days] & 15 & $-11 \%$ & $-5 \%$ & 28 & $-15 \%$ & $+18 \%$ \\
\hline Type II service level* [\%] & 95 & $+2 \%$ & $+1 \%$ & 96 & $+1 \%$ & $-1 \%$ \\
\hline Sea fi & & & $46^{\mathrm{C}}$ & & & \\
\hline Rail freight [\%] & $100 \%$ & $98 \%$ & $54 \%$ & & & \\
\hline Road freight [\%] & & $2 \%$ & & & & $35 \%$ \\
\hline Air freight $[\%]$ & & & & $100 \%$ & $100 \%$ & $65 \%$ \\
\hline
\end{tabular}

Table 2: Summary of metrics for both product types (* average metrics across all markets).

First of all, we observe that it is more costly to run a supply chain for an innovative product than for a functional product (in line with Fisher (1997) and Langenberg et al. (2012)). The main reason is the high degree of supply chain responsiveness required by the innovative product. Our results indicate that the higher responsiveness (i.e. the shorter supply chain average lead time) is achieved in two ways. The innovative product is transported by air freight and, second, it is manufactured in locations closer to markets (see Figure 2). By contrast, because long lead times are not a problem for functional products, slower and cheaper supply chains can be used - taking advantage of lower wages in distant locations and 

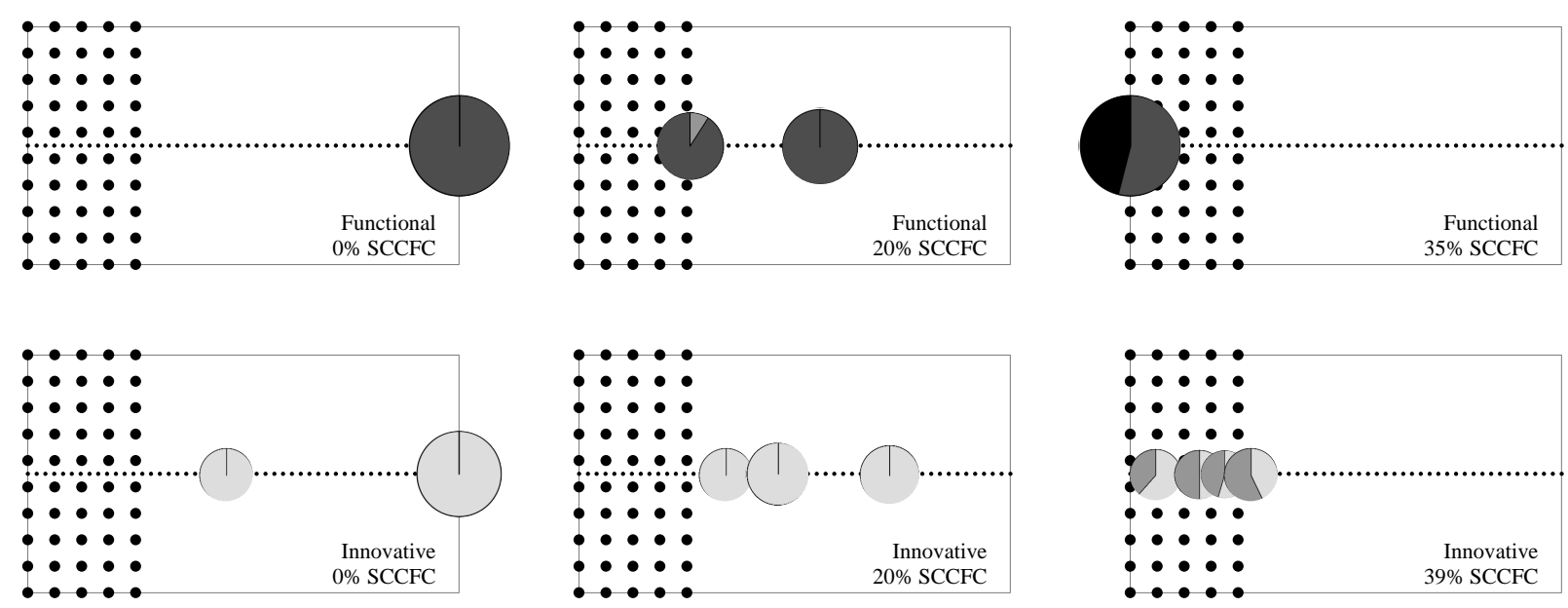

Figure 2: Facility locations for both products, when the SCCFC is increasingly stringent. The size of the circle is proportional to the number of markets served from the facility. The gray slices give the used transport modes: the darker the gray, the slower the mode.

using rail transport. Moreover, in spite of the innovative product's higher holding costs, it is worth keeping higher stock covers and providing higher service levels because penalty costs are higher (see Table 2). With regard to carbon footprints, the innovative product needs a more responsive supply chain with faster transport, leading to larger emissions. As a conclusion, we see that the degree of innovativeness has to be considered when designing the supply chain network and when assessing its carbon footprint.

\subsection{Effects of a supply chain carbon footprint cap (SCCFC)}

Having presented the results for the base case, we now proceed to analyse the effect of a supply chain carbon footprint cap (SCCFC). As noted earlier, an SCCFC policy limits the overall emissions necessary to supply all markets. In the next five subsections, we derive and compare the abatement cost curves for both products, we investigate the effect of the SCCFC on the supply network design, we study the impact of product characteristics in terms of innovativeness and weight, and we explore the case where profit is maximized and markets may be exited.

\subsubsection{Effect on total costs and potential for supply chain carbon abatement}

In this section, we study the effect of supply chain carbon footprint cap (SCCFC) on total costs and, as is common practice, we use the SCCFC to assess the potential for carbon abatement for the two products considered. With the base case as the starting point (see Section 4.2), 
we progressively reduce the supply chain emissions cap by $50 \mathrm{kgCO}_{2}$ per instance as long as it is feasible. This also means that we explore costs-emissions pairs that could be adopted by a company seeking to minimize costs under a SCCFC, i.e. we do not present results for caps that are not binding. The corresponding evolution of the total cost of the supply chain is depicted in Figure 3 (left-hand side). We observe that for a range of caps (down to 11.6 $\mathrm{tCO}_{2} /$ day), the chain supplying the functional product is unaffected as the base case is already less polluting. Then, from $11.6 \mathrm{tCO}_{2} /$ day, the total costs increase regularly for the functional product, while they increase first slightly and then steeply for the innovative product. For both product types, the most stringent feasible cap is around $7.6 \mathrm{tCO}_{2} /$ day. It corresponds to a supply chain with production in the west and slow transport, i.e. leading to minimal manufacturing and transport emissions. For any SCCFC, it is always cheaper to supply the functional product than the innovative one. This is consistent with Fisher (1997), where it is explained that innovative products are usually more costly to supply but give a larger profit margin.

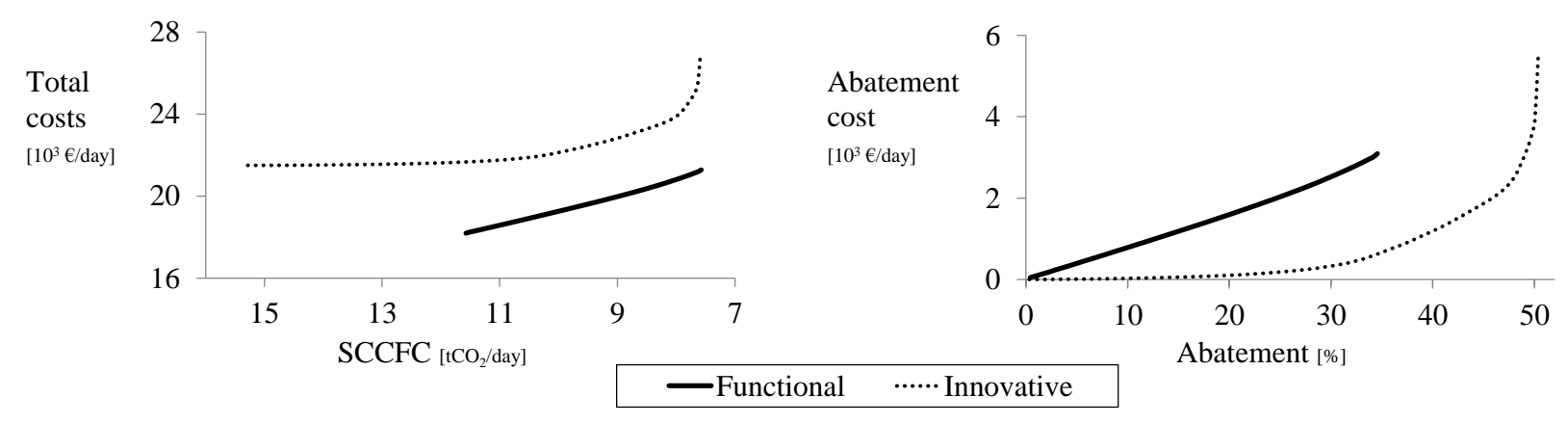

Figure 3: Evolution of the total costs of the supply chain under a SCCFC, and abatement cost curves, for both product types.

The abatement cost curve gives another interesting view on these results (Figure 3, righthand side). The abatement cost is the increase in total costs relative to the reduction in carbon emissions (here expressed in percent), both relative to the base case (i.e. without carbon policy, see Section 4.2). It allows to assess how expensive it is to reduce emissions, starting from the base case situation, and independently of the respective costs and profits of both product types. We first observe that, given the different levels of emissions for the base case, for the innovative product an emission reduction target of up to $50 \%$ is feasible, whereas for the functional product, only a $35 \%$ reduction can be achieved. 
Furthermore, when looking at the abatement cost curve, it appears that, for a wide range of emission reductions, equivalent carbon abatement (in percent) is cheaper for the innovative product than for the functional product. For the functional product, the slope of total costs is significant and quite stable, whereas for the innovative product, it increases very slowly for a wide range of caps and then grows exponentially. For instance, a 10\% reduction implies a cost increase of around $24 €$ /day for the innovative product and of $813 €$ /day for the functional product - both starting from their respective base case. In other words, if a company decides to reduce its $\mathrm{CO}_{2}$ emissions by $10 \%$ while starting from a base case where emissions are not an issue of concern (and with its respective costs and profits), the cost of the abatement will be sensibly smaller if the company supplies innovative products than if it supplies functional products.

If we look at the carbon reduction achieved per additional money spent, the potential for abatement is greater for the innovative product. The main reason for this can be found in the different starting base cases. However, this observation carries over to some extent when absolute emissions caps are considered, as can be observed in the left-hand side of Figure 3. Around $11 \mathrm{tCO}_{2} /$ day, the slope of the curve, i.e. the cost increase, is still sensibly smaller for the innovative product than for the functional product (this is not true for the most stringent caps). In Table 2, we can observe the effect of an emission reduction for both product types. A $39 \%$ carbon reduction for the innovative product results in the same supply chain carbon footprint than a $20 \%$ reduction for the functional one $\left(9.3 \mathrm{tCO}_{2} /\right.$ day $)$. We observe that, to reach this same absolute carbon footprint, the total cost increase is sensibly smaller for the innovative product (5\%) than for the functional product (9\%). In Figure 2, it can be seen that the supply chains are very different (while leading to the same emissions).

To conclude this section, we again observe that the degree of a product's innovativeness, and therefore its supply chain responsiveness requirements, are highly relevant in the definition of supply chain carbon footprint targets. Not all reduction targets are feasible or easily attainable, from a financial perspective, for all firms. A comprehensive model is needed to accurately guide decisions in this regard.

\subsubsection{Effects of SCCFC on the supply chain network}

In this section, we analyse in more detail how the supply network evolves when the SCCFC becomes more and more stringent. Figure 2 shows the facility locations and transport modes 
selected for the functional and the innovative product. It can be seen that, to reduce emissions, facilities move west, to locations closer to market and where technologies are less polluting. In parallel, transport is switched to slower but less polluting modes. A larger number of facilities may also be opened to reduce the average facility-market distance. Table 2 summarizes the metrics for these cases. We can also observe that to meet the caps, in relative as well as in absolute terms, considerably different network designs are deployed for the functional product compared to the innovative product.

Figure 4 presents the complete evolution of four important supply chain metrics as the SCCFC progressively decreases. First, we can observe that the magnitude of emissions from different processes varies considerably by product type. For the functional product, manufacturing emissions are clearly dominant, as slow and less polluting transport modes are used for all caps. For the innovative product, manufacturing and transport emissions have comparable magnitudes in the base case and then progressively converge to similar values as for the functional product.
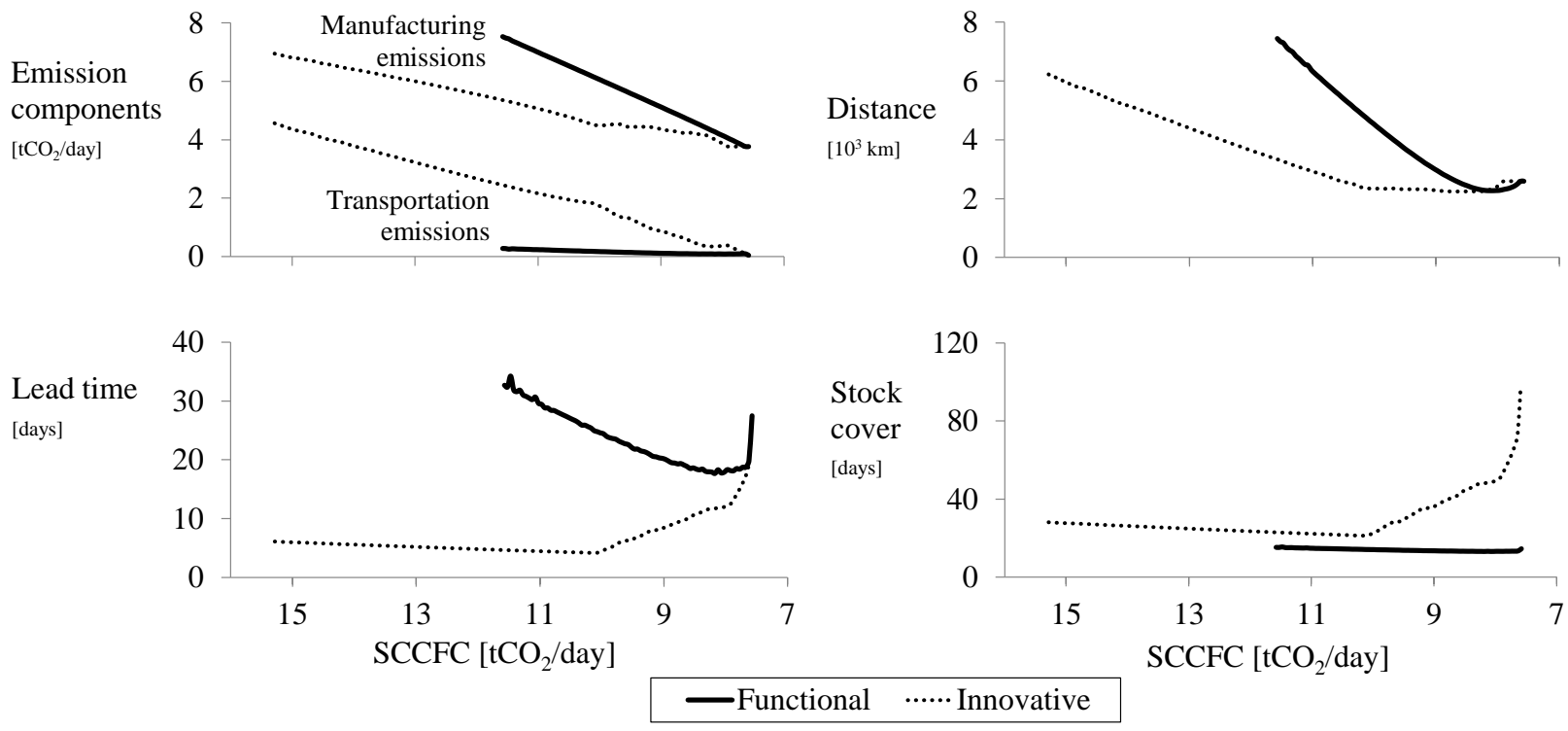

Figure 4: Evolution of supply chain characteristics under a supply chain carbon footprint cap (SCCFC). The left end of the curves reflects the base case; the SCCFC decreases (i.e. the cap stringency increases) as we move right.

With regard to distances between facilities and markets, although for both products manufacturing is progressively shifted to locations closer to the target markets, this occurs at different rates. For the functional product, the slope of the distance curve is more significant. 
This is due to the dominance of manufacturing emissions for this product, which implies that almost all abatement must be achieved by manufacturing in cleaner facilities and, therefore, closer locations. Note that, in Figure 4, the slight increase in the distance for the most stringent caps is caused by the specific setting used, as the average facility-market distance increases when moving facilities west to the cross in Figure 1, while manufacturing emissions are still decreasing.

The impact of carbon caps on the lead time is also different for each product type (see Figure 4), following the different evolution of distance and transport mix (see Figure 2). For the functional product, lead time decreases progressively for most feasible emission caps with reductions of up to 15 days. In contrast, the lead time curve for the innovative product changes slope over time, mostly due to changes in its transport mix, which starts at $100 \%$ air freight and progressively introduces road, rail and even sea freight as caps become more stringent.

With regard to inventory decisions, the different degrees of demand uncertainty result in stock covers that are lower for the functional product than for the innovative one. Since shorter lead times imply lower uncertainty of demand over lead time, we observe that stock covers evolve in close relation to lead times; this is particularly visible for the innovative product. Furthermore, our analyses show that service levels are initially higher for the innovative product, but this is inverted once it becomes too costly to hold larger inventories to compensate for longer lead times.

These examples illustrate that lead time, distance, transport mix and stock cover evolutions are intricate and interdependent, corroborating the need for comprehensive mathematical models to address this problem. In sum, our results illustrate the complexity of operational and environmental trade-offs and confirm that product innovativeness should be taken into account when assessing the impact of supply chain carbon caps on optimal network design.

\subsubsection{Sensitivity analysis on product innovativeness}

In the previous experiments, we focus on two illustrative products with clearly distinct characteristics: a functional and an innovative product. Our goal in this section and the next one is to provide a sensitivity analysis on product characteristics. Here, we explore a range of products from highly functional (coefficient of variation of demand $C V=0.1$; profit margin $p m=3 \%)$ to highly innovative $(C V=2 ; p m=75 \%)$, including the previously studied 
functional $(C V=0.2 ; p m=5 \%)$ and innovative $(C V=1.5 ; p m=40 \%)$ products. Several observations can be made on the results presented in Figure 5. First, as expected, the more innovative a product is, the more costly it is to supply.

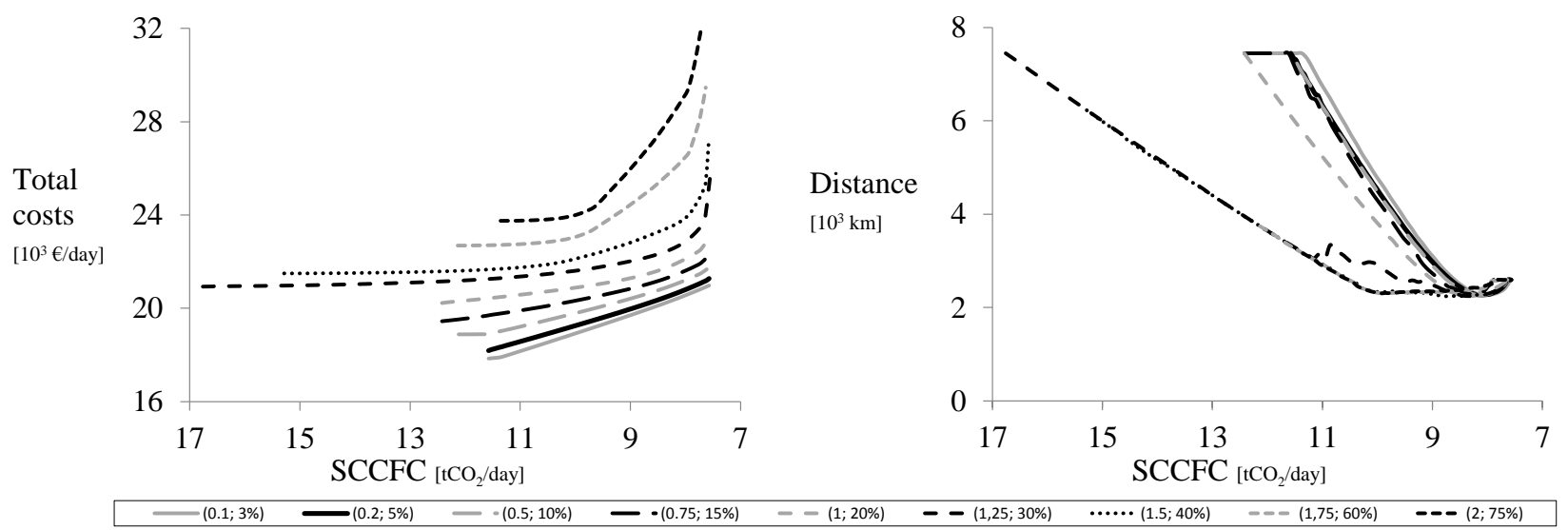

Figure 5: Evolution of the total costs and the average facility-market distance under SCCFC, for a range of products with increasing degree of innovativeness. The legend gives $(C V ; p m)$, the coefficient of variation of demand and the profit margin for each product.

Next, let us focus on the base case (left end of the curves). Figure 5 shows that the base case emissions are non-monotonic with product's innovativeness, i.e. they initially increase but then decrease. Looking at the corresponding supply networks, it appears that, for the most functional products, a single facility in the east and a slow transport mode are used, accepting long lead times to reduce costs. When the innovativeness of the products increases, the facility is kept in the east but transport is switched to faster modes. The corresponding $\mathrm{CO}_{2}$ emissions thus rise until only air transport is used, leading to maximum emissions (16.8 $\mathrm{tCO}_{2} /$ day when $C V=1.25$ and $p m=30 \%$ ). For these products (with $C V$ up to 1.25 and $p m$ up to $30 \%$ ), the average facility-market distance is maximal for the base case (see the right-hand side of Figure 5). Then, when product innovativeness further increases, even more responsive supply chains are needed and the only option to reduce lead time is to bring facilities closer to markets. The emissions thus decrease again, and the distance is reduced (see Figure 5).

When a SCCFC is imposed, emissions can essentially be reduced in two ways: moving facilities to the west (reducing distances and manufacturing emissions), or switching to slower less polluting transport modes. The optimal way to reduce emissions is however highly dependent on each product's characteristics. From our analyses, we observe that, for the most 
innovative products $(C V \geq 1.25$ and $p m \geq 30 \%)$ caps are met firstly by decreasing distances to markets (see the right-hand side of Figure 5), and subsequently by switching to slower transport modes (leading to a rise in inventory and total costs, see the left-hand side of Figure 5). In contrast, for the most functional products, transport is switched to slower modes first (if possible) and distances are reduced next. This again highlights the complexity of the trade-offs at hand, and the importance of product's characteristics (related to innovativeness in particular) when studying supply network design and carbon emissions.

\subsubsection{Sensitivity analysis on product weight}

In this section, we comment on the impact of a product's weight on the supply chain design and on carbon emissions. For this, we analyse innovative products with different weights, varying from 0.02 to $5 \mathrm{~kg}$ per unit (all previous experiments were conducted with weights of $0.2 \mathrm{~kg}$ per unit, similar conclusions may be derived with the functional product). In our model, a product's weight firstly impacts transport costs and emissions (equations (14) and (19)). Figure 6 shows how this translates to the total costs and on the facility-market distance when the SCCFC becomes more stringent. Unsurprisingly, the heavier the product, the higher the costs to supply it.

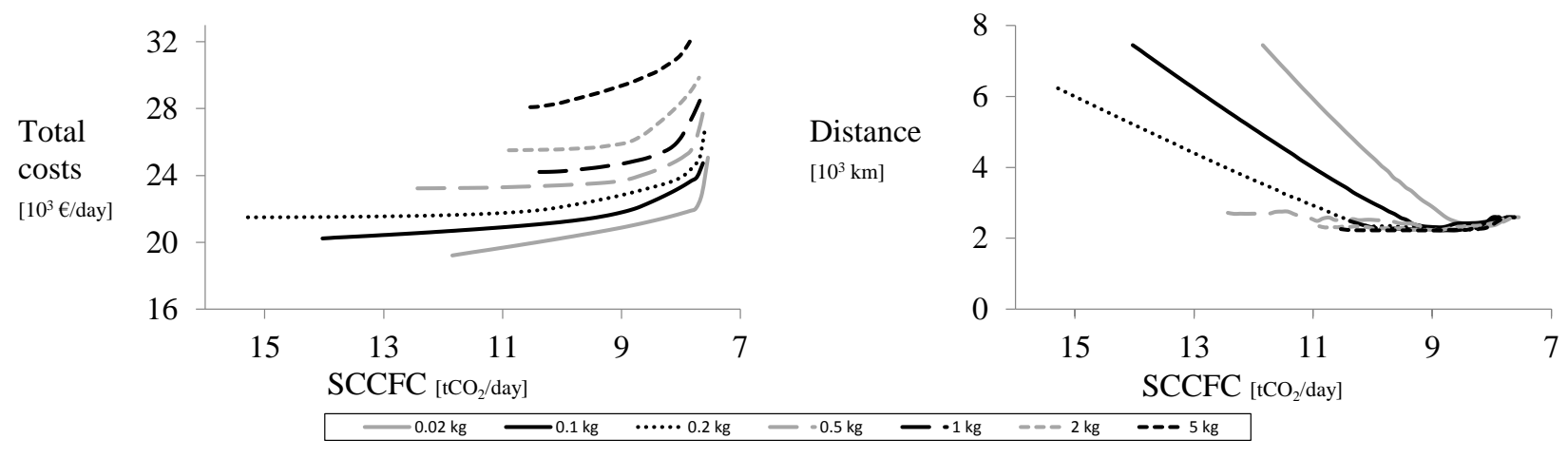

Figure 6: Evolution of the total cost and the average facility-market distance under SCCFC, for a range of innovative products with increasing weights.

Looking at the base case for different product weights (left end of the curves), we observe again a complex non-monotonic evolution. As products become heavier, transport costs become more important. For light products (0.02 and $0.1 \mathrm{~kg}$ ), facilities are located in the far east, and air transport is used. Emissions increase, as they are also proportional to the weight. When transport costs become too high, facilities are brought closer (from $0.2 \mathrm{~kg}$, 
see the right-hand side of Figure 6). Soon, facilities are located as close as possible, and, to keep costs to the minimum as the product's weight increases, transport is switched to cheaper modes. For these heavy products (from $0.5 \mathrm{~kg}$ ), the impact on carbon emissions is non monotonic, as two opposed effects coexist: transport using the same mode becomes more polluting as the weight increases, while transport is also switching to cleaner modes to decrease costs.

Regarding the evolution of the supply chain when a SCCFC is applied, we observe a behaviour similar to the one described in the previous section. When aiming to reduce emissions for the innovative product, facilities are first brought closer to markets (see the right-hand side of Figure 6). When we reach the point where facilities are close, transport modes are modified and it becomes significantly more expensive to reduce emissions (see the left-hand side of Figure 6).

\subsubsection{Profit maximisation and market selection}

In our model, and in the previous experiments, we supposed that companies were minimising total costs while serving all markets and complying with a carbon footprint policy. However, as emission policies increase costs (see Figure 3), some markets may become unprofitable,

and, therefore, the company may decide to exit them (or to increase the selling price). To consider this case, we reformulate our model to a profit maximisation problem, where the company is allowed to exit any market. For this, only equations (1-2) need to be modified. They are replaced by equations (23-24), respectively.

$$
\begin{aligned}
\max _{Y_{m f t}, Z_{f}} & \sum_{m, f, t}\left(\text { sellingprice }_{m}-\text { unitcost }_{m f t}^{C}\right) \lambda_{m} Y_{m f t}-\sum_{f} c_{f}^{F} Z_{f} \\
\text { s.t. } & \sum_{f, t} Y_{m f t} \leq 1 \quad \forall m
\end{aligned}
$$

The objective function (23) captures the total profit per unit of time, where sellingprice ${ }_{m}$ is the selling price per unit. Constraint (24) ensures that each market is not served by more than one facility/transport mode combination. Unlike before, the result of the summation is allowed to be zero, in which case the market is not served.

We use the adjusted model for the two products presented in Section 4.1, and illustrate the impact of carbon caps in the selection of markets to be served in a profit maximisation context, with different selling prices (including the previous values for the functional, $4.21 €$, and the innovative product, $7.5 €$, same for all markets). Several interesting observations can be derived from Figure 7. In the base case (left end of the curves), all 50 markets are served 
for all the products we analysed. The supply networks, the distances, and the $\mathrm{CO}_{2}$ emissions are thus the same as in the cost minimisation case (see Figures 4 and 3). This stays true when a SCCFC is introduced, as long as all markets are served. In these cases, total profits evolve oppositely to total costs. However, when the SCCFC becomes more stringent, the company starts exiting some markets because they become unprofitable. The cap at which markets are exited depends on each product (see Figure 7). Unsurprisingly, the average distance drops at this point as the most distant markets are exited first, and profits further decrease as less markets are served. Ultimately, the zero emission SCCFC can be attained theoretically, with zero markets being served. Another interesting observation is that the previously studied functional product (with selling price at $4.21 €$ ) is profitable in all markets only when there is no SCCFC. As soon as a cap is introduced, the most distant markets start to be exited.

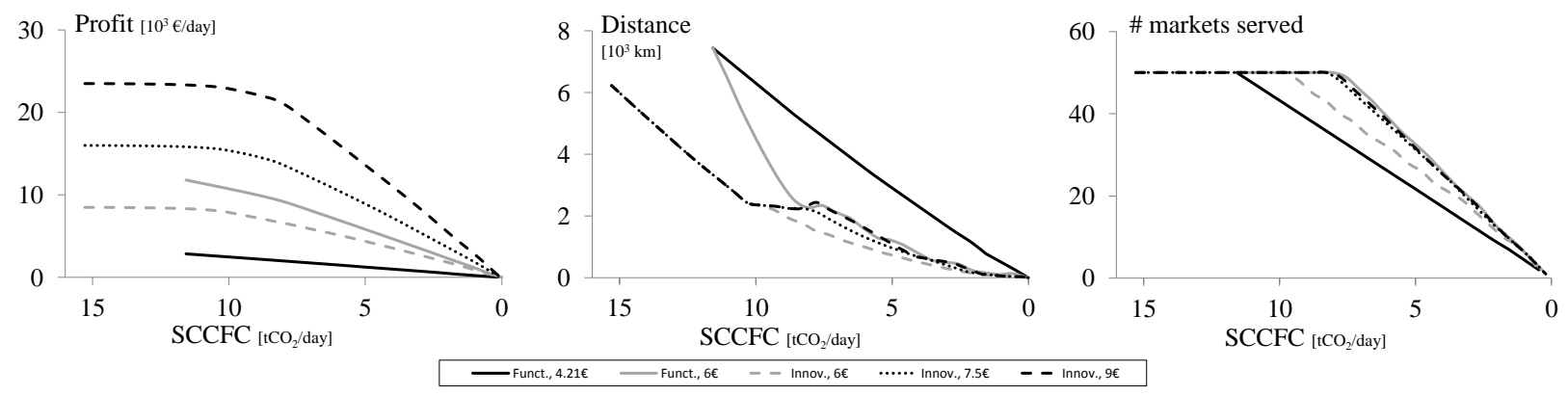

Figure 7: Evolution of the profit, the average facility-market distance, and the number of markets served, under SCCFC policy, for functional and innovative products with various selling price. The legend gives the product type and the selling price.

To further illustrate the profit maximisation model, we conduct additional experiments for the previously studied innovative product (see Section 4.1), but with a different geographical setting. In this setting, the markets and potential facility locations are uniformly distributed in a squared area $\left(8000^{2} \mathrm{~km}^{2}\right)$, as shown in Figure 8. The same figure shows the selected facility locations, the transport modes used, and the markets served for different caps. Transport mode and distance (by increasing the number of facilities) are the first levers used to reduce carbon emissions. But, when the SCCFC becomes too stringent, some markets are exited, ending up in a supply chain configuration made of clusters with facilities serving close-by markets around them. 

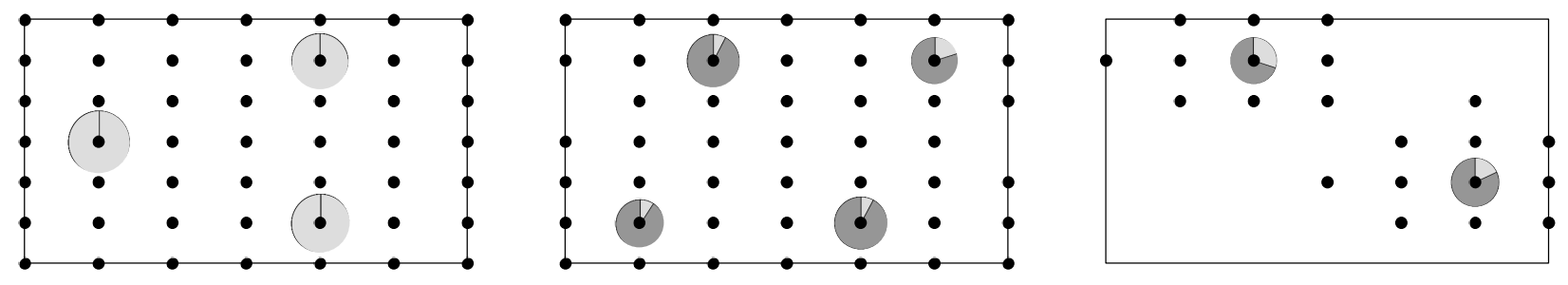

Figure 8: Facility locations, on a uniform geographical setting, for the innovative product, when profit is maximized and when the SCCFC is increasingly stringent (base case 11.1, 9.1, and $4.1 \mathrm{tCO}_{2} /$ day). The size of the circle is proportional to the number of markets served from the facility. The gray slices represent the transport mix: the darker the gray, the slower the mode. The black dots represent the markets served.

\subsection{Market vs. supply chain carbon footprint cap}

Continuing with our two product example (see Section 4.1), we now compare the overall supply chain cap policy (SCCFC) vs. imposing a carbon footprint cap on each market (MCFC), constant across markets. As discussed in Section 3.2.2, an MCFC is more constraining than an SCCFC because compensation of emissions across markets is not allowed. To provide some intuition, we first observe that, for the base case (without carbon policy), the variability, or dispersion, of carbon footprints across all markets equals 0.02 for the functional product and 0.17 for the innovative one. This means that there is more compensation across markets for the latter. Hence, we expect a greater MCFC vs. SCCFC difference for the innovative product, than for the functional one, as compensation is allowed with an MCFC. With our models, we are able to quantify this difference.

Figure 9 illustrates the evolution in the MCFC vs. SCCFC difference as caps become more stringent. To look at comparable caps, we introduce an MCFC (the same across markets) such that $\sum_{m} M C F C_{m}=S C C F C$, i.e. so that the imposed total supply chain carbon abatement is the same with the two policies. Note that we focus here on absolute caps while $\%$ reduction could also be considered. As Figure 9 shows, all curves for the functional product oscillate around zero, whereas those for the innovative product show larger differences between the two policies. This confirms that the MCFC vs. SCCFC differences are greater for the innovative product. We also observe that, for the innovative product, the MCFC vs. SCCFC difference is particularly important for lead time and distance. Moreover, we measured that, when switching from SCCFC to MCFC, the number of facilities goes from 2.9 to 4.2 for the innovative product, and only from 1.8 to 2 for the functional product (on average over tested 
caps). However, although higher for the innovative product, the difference in total costs is relatively small for both products. Hence, an important observation from this analysis is that although meeting an MCFC is not much more expensive than meeting an SCCFC for either product type, for the innovative product there are substantial implications in the network design to meet either one policy variant or the other.

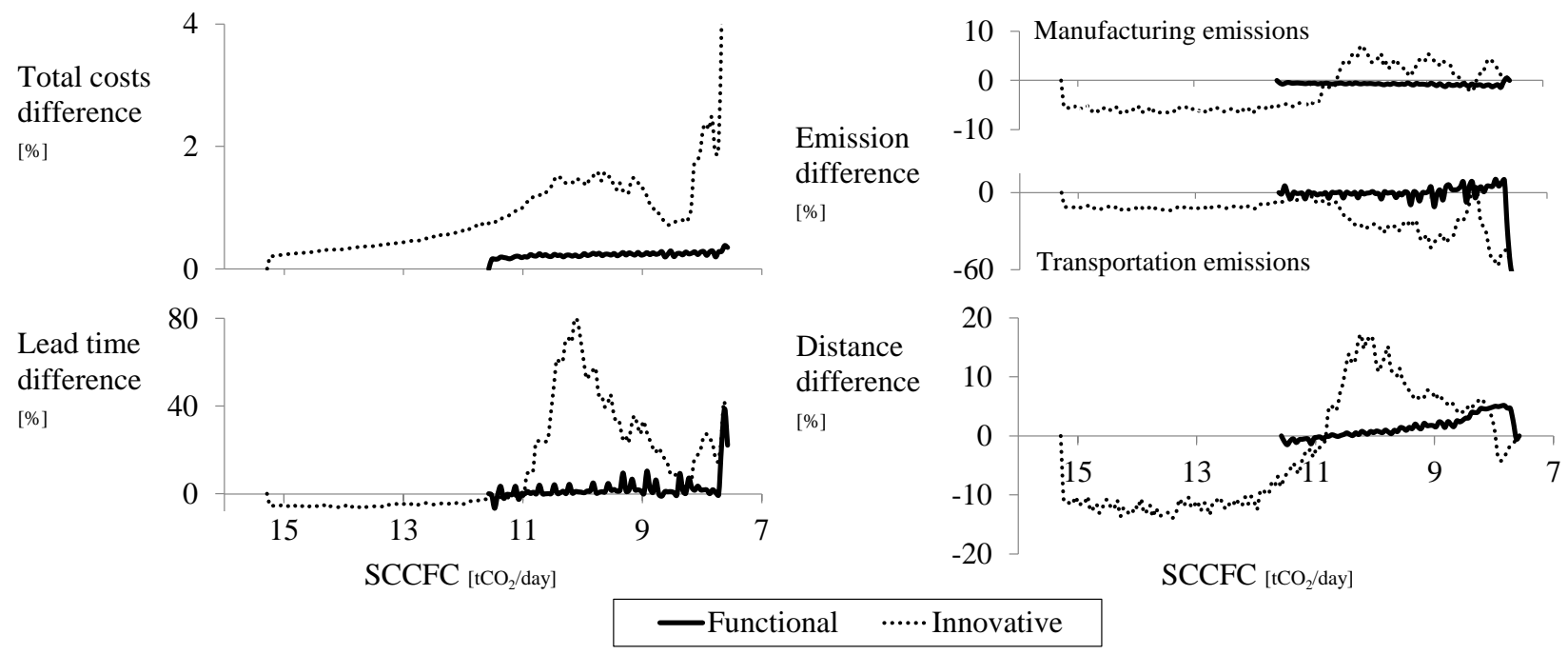

Figure 9: Effect of a market carbon footprint cap relative to that of a supply chain carbon footprint cap, measured as the percentage difference for four supply chain characteristics.

\subsection{Supply chain carbon footprint cap and tax equivalence}

In the field of environmental economics, it is well-known that tax and cap policies are in fact deeply related (Weitzman, 1974). To understand this, the notion of marginal abatement cost (MAC) curve has to be introduced. The MAC curve links a firm's emission levels and the cost of additional units of pollution reduction, i.e. it is the change in abatement cost per unit change in abatement. Then, from a theoretical point of view (Weitzman, 1974), if a tax is set equal to a firm's MAC curve for a level of abatement and the firm tries to minimise its costs, the tax will induce the firm to achieve that level of abatement, which could otherwise be achieved by imposing a cap. This is due to the fact that it will be optimal for the company to abate up to the level at which the MAC is equal to the tax. Indeed, as long as the MAC is lower than the tax, it will be cheaper to change to less polluting supply chain configuration than to pay the tax. However, for levels of abatement with higher MAC than the tax, it will be cheaper for the company to pay the tax than to abate further. 
According to this theory, using our supply chain carbon footprint cap (SCCFC) model, we can derive the levels of supply chain carbon footprint tax (SCCFT) that should a priori induce a desired level of carbon abatement, and the marginal abatement cost (MAC) curves give us an indication on these levels for a given company with a given context. In Figure 10, we show the MAC curves for both product types, derived from the previously presented abatement cost curves (Figure 3), i.e. relying on the SCCFC model. For the functional product, a supply chain carbon tax must be as high as $580 € / \mathrm{tCO}_{2}$ to trigger any emission reductions. In contrast, for the innovative product, around $2 \mathrm{tCO}_{2}\left(4 \mathrm{tCO}_{2}\right)$ would be reduced daily with a tax of only $45 € / \mathrm{tCO}_{2}\left(152 € / \mathrm{tCO}_{2}\right)$. To put these figures in perspective, the price of one $\mathrm{EU}$ Allowance (EUA) has varied between 0 and $30 € / \mathrm{tCO}_{2}$ since the launch of the EU Emission Trading Scheme (EU ETS) in January 2005 (EEX, 2011). This means that, with the current carbon prices, a supply chain carbon tax would not induce any abatement for the functional product; however, it would derive substantial reductions for the innovative product. This also implies that the supply chain carbon tax has a selective effect on product types: for this example, it brings the innovative product's manufacturing base closer to markets, but not the manufacturing base of the functional one.
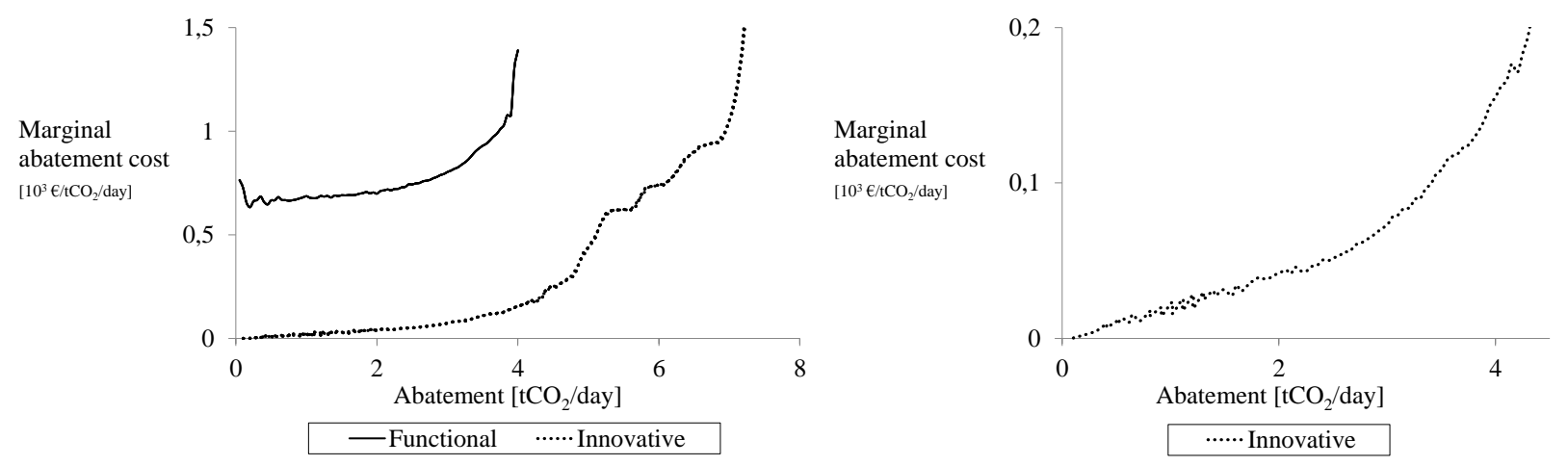

Figure 10: Marginal abatement cost (MAC) curves for both product types. The right-hand side zooms in on small marginal abatement costs, i.e. realistic on carbon taxes.

Having derived the levels of an SCCFT (the MAC) that should theoretically induce a desired level of abatement, we now check whether it indeed holds in our setting. For each product type, we use our SCCFT model variant with the values of the MAC curves as tax level. The results we obtain indicate that the percentage difference in supply chain emissions between both policies (SCCFT vs. SCCFC) is relatively low for most levels of abatement 
(right-hand side of Figure 11) - the mean absolute deviation (MAD) is $1.2 \%$ and $0.7 \%$ for the functional and the innovative product respectively. Therefore, the equivalence between price (tax) and quantity (cap) instruments directionally holds, especially for the innovative product. The small difference observed may be related to the non-differentiability of our MAC curves, as the policy equivalence holds on the assumption that cost and benefit functions are convex, continuous and twice differentiable (Weitzman, 1974).

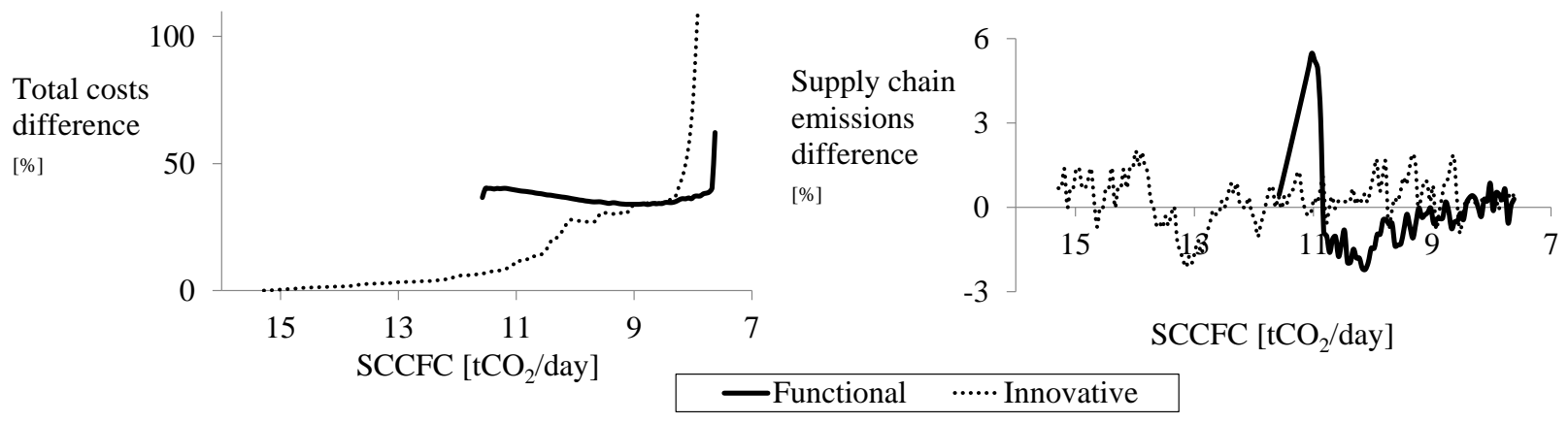

Figure 11: Effect of a supply chain carbon footprint tax relative to that of a supply chain carbon footprint cap (SCCFT vs. SCCFC), where the MAC values are used as SCCFT.

In addition to comparing emission levels, it is interesting to look at total costs. As the left-hand side of Figure 11 illustrates, the total supply chain costs are considerably higher with a price policy (tax) than with a quantity policy (cap). In the case of a cap, the cost increment bared by the company is shown on Figure 3. In the case of a tax set to reach the same level of abatement, the company will pay these same costs plus the tax for the remaining carbon it will still be emitting. Accordingly, and in line with theory, this cost difference increases with the slope of the marginal abatement cost curve. Comparing figures 10 and 11, it can be seen that the MAC (thus the induced tax) and the SCCFT vs. SCCFC cost difference are proportional. In particular, for the innovative product, the MAC and the cost difference are first small and then increase proportionally from around $5 \mathrm{tCO}_{2} /$ day abatement.

Finally, we note that the network design remains relatively similar for both policies, especially once again, for the innovative product. Summarising this analysis, we can conclude that, using the MAC values as supply chain carbon taxes we obtain comparable levels of carbon abatement and similar network designs; however, total supply chain costs are considerably higher with a price policy than with a quantity policy. 


\section{Conclusions}

A company's operational and environmental performances are clearly interrelated. In our research, we explored the inherent trade-off between carbon footprints and supply chain responsiveness employing a mathematical model for supply chain network design. Our model differs from prior work in that it simultaneously considers multiple supply chain processes and explicitly captures supply chain responsiveness requirements, through the inclusion of demand uncertainty and decisions on lead time. We conducted numerical analyses to demonstrate the relevance of the trade-offs modelled and to illustrate the type of managerial insights that our model allows to derive. In particular, we analysed the impact of different carbon policies: a supply chain carbon footprint cap (SCCFC), a market carbon footprint cap (MCFC) and a supply chain carbon footprint tax (SCCFT).

Our numerical analyses contribute to the understanding of carbon policy implications for supply chains. Companies can use our modelling approach and fine-tune it to their specific parameters in order to define comprehensive and cost-effective carbon abatement strategies to meet a given policy, either imposed or voluntarily adopted. Policy makers, in turn, can draw on our analyses to gauge the relative impact of carbon policies on supply chain costs and network design. In addition, decision makers can assess how different product types, ranging from purely functional to highly innovative ones, are affected by different carbon polices.

From our analyses, we showed that the product's characteristics, and the degree of innovativeness in particular, strongly affects the supply chain network design, the cost and potential for carbon abatement, as well as the levers used to decrease emissions. Hence, product innovativeness is highly relevant in the definition of carbon footprint targets. Analyses with increasingly stringent supply chain carbon footprint caps (SCCFC) revealed non-monotonic evolutions of transport mixes, lead times, distances and stock covers, which corroborate the importance of using mathematical models for the problem addressed. We also showed that the model can easily be adapted in the case where profit is maximized and markets may be exited.

Comparing the imposition of a cap on market vs. supply chain carbon footprints (MCFC vs. SCCFC), we conclude that an MCFC becomes relatively more constraining than an SCCFC as the dispersion in the carbon footprints of products sold across markets increases. Moreover, we observe that meeting an MCFC is not much more expensive but can have 
an important impact on the network design. Regarding the SCCFT policy, we have shown that, in our setting, the traditional equivalence between price and quantity instruments holds directionally. Comparable levels of abatement can be achieved with both policies, and the tax values can be derived a priori from the marginal abatement cost (MAC) curves. Although the optimal network design for these two policies remains similar, total costs are higher when there is a tax on supply chain carbon emissions rather than a cap.

With this research, we hope to contribute to a better understanding of carbon footprint and supply chain responsiveness trade-offs, and their implications on the supply chain network design. Numerous facets of carbon management remain to be explored and the potential for contributions from operations management researchers is substantial. The relevance of distinguishing between functional and innovative products could be further explored in more complex settings. Dynamic and stochastic programming models would be insightful in studying changes in carbon policies over multiple planning periods including network reconfiguration capabilities. Moreover, deriving robust configurations where effects of different products are pooled could be useful in product portfolio strategic decisions. Cap and trade policies could also be studied in a setting with multiple firms. Finally, we believe that further efforts to merge existing knowledge in environmental economics and environmental supply chain management are necessary. From the regulator's perspective, it would be relevant to integrate uncertainty in abatement cost curves and, from the firm's perspective, to consider uncertainty in carbon prices.

\section{References}

Alonso-Villar, O., 2005. The effects of transport costs revisited. Journal of Economic Geography $5(5), 589-604$.

Baumol, W., Vinod, H., 1970. An inventory theoretic model of freight transport demand. Management Science 16 (7), 413-421.

Benjaafar, S., Li, Y., Daskin, M., 2013. Carbon footprint and the management of supply chains: insights from simple models. IEEE Transactions on Automation Science and Engineering 10 (1), 99-116.

Blauwens, G., Vandaele, N., Van de Voorde, E., Vernimmen, B., Witlox, F., 2006. Towards 
a modal shift in freight transport? A business logistics analysis of some policy measures. Transport Reviews 26 (2), 239-251.

Bloemhof-Ruwaard, J. M., Van Wassenhove, L. N., Gabel, H. L., Weaver, P. M., Dec. 1996. An environmental life cycle optimization model for the European pulp and paper industry. Omega 24 (6), 615-629.

BSI, 2008. PAS 2050:2008-specification for the assessment of the life cycle greenhouse gas emissions of goods and services. British Standards Institution (BSI).

Carlsson, D., Rönnqvist, M., 2005. Supply chain management in forestry-case studies at Södra Cell AB. European Journal of Operational Research 163 (3), 589-616.

Chaabane, A., Ramudhin, A., Paquet, M., 2012. Design of sustainable supply chains under the emission trading scheme. International Journal of Production Economics 135 (1), 37-49.

Chen, C., Monahan, G., 2010. Environmental safety stock: the impacts of regulatory and voluntary control policies on production planning, inventory control, and environmental performance. European Journal of Operational Research 207 (3), 1280-1292.

Comas Martí, J. M., Seifert, R. W., 2013. Assessing the comprehensiveness of supply chain environmental strategies. Business Strategy and the Environment 22 (5), 339-356.

Defra, 2010. Guidelines to Defra/DECC's greenhouse gas conversion factors for company reporting.

Dekker, R., Bloemhof, J., Mallidis, I., 2012. Operations research for green logistics an overview of aspects, issues, contributions and challenges. European Journal of Operational Research 219 (3), 671-679.

Diabat, A., Simchi-Levi, D., 2009. A carbon-capped supply chain network problem. IEEE International Conference on Industrial Engineering and Engineering Management, IEEM.

Drake, D., Kleindorfer, P., Van Wassenhove, L., 2010. Technology choice and capacity investment under emissions regulation. INSEAD. Working paper.

EEX, 2011. EU emission allowances. Prices and trading volumes (2011/11/22). European Energy Exchange, http://www.eex.com.

Fisher, M. L., 1997. What is the right supply chain for your product? Harvard Business Review 75 (2), 105-116. 
Fleischmann, M., Bloemhof-Ruwaard, J. M., Dekker, R., van der Laan, E., van Nunen, J. A. E. E., Wassenhove, L. N. V., 1997. Quantitative models for reverse logistics: a review. European Journal of Operational Research 103 (1), 1-17.

GHG Protocol, 2004. A corporate accounting and reporting standard. World Business Council for Sustainable Development (WBCSD) and World Resources Institute (WRI).

Hadley, G., Whitin, T., 1963. Analysis of inventory systems. Prentice Hall.

Harris, I., Naim, M., Palmer, A., Potter, A., Mumford, C., 2011. Assessing the impact of cost optimization based on infrastructure modelling on co2 emissions. International Journal of Production Economics 131 (1), 313-321.

Hoen, K., Tan, T., Fransoo, J., van Houtum, G., 2014. Effect of carbon emission regulations on transport mode selection under stochastic demand. Flexible Services and Manufacturing Journal 26 (1-2), 170-195.

Hua, G., Cheng, T., Wang, S., 2011. Managing carbon footprints in inventory management. International Journal of Production Economics 132 (2), 178-185.

Hugo, A., Pistikopoulos, E. N., 2005. Environmentally conscious long-range planning and design of supply chain networks. Journal of Cleaner Production 13 (15), 1471-1491.

IPCC, 2006. Guidelines for national greenhouse gas inventories.

Krugman, P., Venables, A. J., 1995. Globalization and the inequality of nations. Quarterly Journal of Economics, 857-880.

Langenberg, K. U., Seifert, R. W., Tancrez, J.-S., 2012. Aligning supply chain and product portfolios. International Journal of Production Economics 135 (1), 500-513.

Meixell, M., Norbis, M., 2008. A review of the transportation mode choice and carrier selection literature. International Journal of Logistics Management 19 (2), 183-211.

Nahmias, S., 1997. Production and operations analysis, 3rd Edition. Irwin.

Quariguasi Frota Neto, J., Walther, G., Bloemhof-Ruwaard, J., van Nunen, J. A. E. E., Spengler, T., 2009. A methodology for assessing eco-efficiency in logistics networks. European Journal of Operational Research 193 (3), 670-682.

Sahin, G., Süral, H., Aug. 2007. A review of hierarchical facility location models. Computers \& Operations Research 34 (8), 2310-2331.

Seifert, R. W., Langenberg, K. U., 2011. Managing business dynamics with adaptive supply chain portfolios. European Journal of Operational Research 215 (3), 551-562. 
Srivastava, S. K., 2008. Network design for reverse logistics. Omega 36 (4), 535-548.

Storper, M., 1992. The limits to globalization: Technology districts and international trade. Economic Geography 68 (1), 60-93.

Tadikamalla, P., 1984. A comparison of several approximations to the lead time demand distribution. Omega 12 (6), 575-581.

The Carbon Trust, July 2011a. Consumer demand for lower-carbon lifestyles is putting pressure on business. Carbon Trust Viewpoint.

The Carbon Trust, June 2011b. Raising the bar-building sustainable business value through environmental targets (CTA003).

Tyworth, J., 1991. The inventory theoretic approach in transportation selection models: a critical review. Logistics and Transportation Review 27 (4), 299-318.

Wang, F., Lai, X., Shi, N., 2011. A multi-objective optimization for green supply chain network design. Decision Support Systems 51, 262-269.

Weitzman, M., 1974. Prices vs. quantities. The Review of Economic Studies 41 (4), 477-491.

Wilhelm, W., Liang, D., Rao, B., Warrier, D., Zhu, X., Bulusu, S., 2005. Design of international assembly systems and their supply chains under NAFTA. Transportation Research Part E: Logistics and Transportation Review 41 (6), 467-493. 